\title{
Evaluation of a sticky trap (AedesTraP), made from disposable plastic bottles, as a monitoring tool for Aedes aegypti populations
}

Eloína Maria Mendonça de Santos ${ }^{1,2^{*}}$, Maria Alice Varjal de Melo-Santos², Claudia Maria Fontes de Oliveira², Juliana Cavalcanti Correia ${ }^{1}$ and Cleide Maria Ribeiro de Albuquerque ${ }^{1}$

\begin{abstract}
Background: Dengue virus, which is transmitted by Aedes aegypti mosquitoes is the most important emerging viral disease, infecting more than 50 million people annually. Currently used sticky traps are useful tools for monitoring and control of A. aegypti, despite differences in efficiency, labor requirements and cost. In the present work, a field assay was carried out to evaluate the performance of a sticky trap (AedesTrap), produced using disposable material, in capturing gravid Aedes spp. females. Additionally, conditions necessary for the improved performance of the device, such as number of traps per site and location (indoors or outdoors) were evaluated.

Methods: During a one year period, traps were placed in a dengue endemic area in 28 day cycles. The trap, named AedesTrap, consisted of a disposable plastic soda bottle coated inside with colophony resin, which served as a sticky substrate. Disposable bottles were donated by restaurants, and traps were made by laboratory staff, reducing the cost of the sticky trap (less than $U \$ 3$ ). Mosquito capture in indoor and outdoor areas was compared by placing the traps in laundry room, kitchen or bedroom (indoors) and front or back yard (outdoors). The relationship between the number of AedesTraps and quantity of captured mosquitoes was investigated by utilizing one or three traps/site.
\end{abstract}

Results: During a 28 day cycle, a single AedesTrap was capable of capturing up to $15 \mathrm{~A}$. aegypti in a house, with a mean capture of 0.5 to 2.63 females per premise. The AedesTrap collected three times more outdoors versus indoors. Similarly, the capability of detecting Aedes spp. infestation, and of capturing females, was three times higher when using three AedesTraps per house, compared with one trap per house.

Conclusions: AedesTrap was shown to be capable of capturing A. aegypti and other culicidae, providing information on the adult mosquito population, and allowing the identification of areas critically infested by mosquitoes. Low requirements for skilled labor together with easy maintenance and low cost are additional advantages of using this sticky trap.

Keywords: Aedes female, Sticky trap, Locality, Ovitrap, Surveillance

\section{Background}

As the most effective vector of important arboviruses such as yellow fever and dengue, Aedes aegypti (Linnaeus, 1762) represents a major threat to health in tropical regions. Despite the efforts of scientists and health service

\footnotetext{
* Correspondence: eloina.santos@gmail.com

* Correspondence: eloina.santos@gmail.com
'Laboratory of Terrestrial Invertebrates, Department of Zoology, Center of Biological Sciences, Universidade Federal de Pernambuco. Av. Moraes Rego s/n, Cidade Universitária, Recife, PE CEP: 50670-420, Brazil

${ }^{2}$ Department of Entomology, Centro de Pesquisas Aggeu Magalhães,

Fundação Oswaldo Cruz. Av. Moraes Rego s/n, Cidade Universitária, Recife, PE CEP: 50670-420, Brazil
}

professionals, current methods for the surveillance and control of this mosquito species have been inadequate, requiring the development of new approaches for the control of the insect [1].

Conventional methods of monitoring and controlling $A$. aegypti differ in efficiency and labor requirements. Collection techniques such as backpack aspirators [2,3] and the BG-Sentinel [4], provide reliable samples, however, both require a power source and are highly labor intensive, rendering daily mosquito collection in dengue endemic areas not cost-effective [5,6]. Furthermore, 
several aspects, such as operator competence, site of collection (e.g. indoors vs. outdoors), site size, the presence of furniture, and the duration of sampling may influence manual collection results [5,6]. Some mosquito traps have been developed specifically to capture gravid A. aegypti. Sticky ovitraps [5,7] and the Adultrap [8,9] are examples of traps for $A$. aegypti females. An alternative strategy using adhesive material to capture the female during oviposition are different models of single sticky ovitraps $[5,7,10]$ and double sticky traps $[7,11]$. These are based on ovitraps, which are originally made from black jars filled with water and provided with a hardboard paddle on which females laid their eggs [12]. Ovitraps are inexpensive and simple to assemble and operate. They are widely used to obtain information derived from number of eggs laid, and to assess the spatial/temporal distribution of mosquitoes [5,13].

Sticky traps are used to easily identify the species of mosquito and allow a direct count of the number of adults that have visited the trap. These traps have also been used to monitor mosquito population dynamics [5] and to investigate the ecological parameters of $A$. aegypti and Aedes albopictus in relation to eco-climatic factors $[14,15]$. In addition, dengue surveillance $[16,17]$, dispersal of dengue vectors $[3,16,18,19]$ and evaluation of the effectiveness of vector monitoring strategies [14] have been performed using sticky traps. The effective performance of sticky traps is a stimulus to the development of low-cost models to be used more widely by health services. The present study reports the results of field trials designed to evaluate the performance of sticky traps (AedesTrap), made from disposable bottles, in capturing Aedes spp. Conditions under which the AedesTrap use could be improved are also described.

\section{Methods}

\section{Study area}

The study was carried out in Engenho do Meio, an urban area with an area of $0.89 \mathrm{~km}^{2}$ and a population density of 11,865 habitants $/ \mathrm{Km}^{2}$, situated in the city of Recife (22 03' 20.7" S 34 56' 43.6"W), in the north east of Brazil. The study area included mainly residential properties, usually with a back or front yard, covered with vegetation. Although control activities based on larval surveys, larvicides application, environmental management, education and mobilization have been performed in the area since 1996, by the National Program of Dengue Control (PNCD), entomological surveillance data shows that it has been continuously infested by A. aegypti [19]. An intermittent water supply, deprived sanitation conditions, high temperatures (ranging from $22^{\circ} \mathrm{C}$ to $32^{\circ} \mathrm{C}$ ) and relative air humidity $(70 \%$ - 90\%) throughout the year, provide excellent conditions for mosquitoes to breed, which explains the continued presence of $A$. aegypti in the study area [19].
During the present study, weather variables were obtained from the National Institute of Meteorology (INMET), situated approximately $3.5 \mathrm{~km}$ from the study area.

\section{Trap design}

The design of the trap for the collection of adults consisted of a disposable plastic soda bottle $(2 \mathrm{~L}), 20 \mathrm{~cm}$ in length and $10 \mathrm{~cm}$ in width, painted black on the outside. Rubber material, $20 \mathrm{~cm}$ in length and coated on one side with colophony resin was placed inside the bottle, and served as a sticky substrate. This trap model was named the AedesTrap (Figure 1). Traps were labeled showing date and trap number.

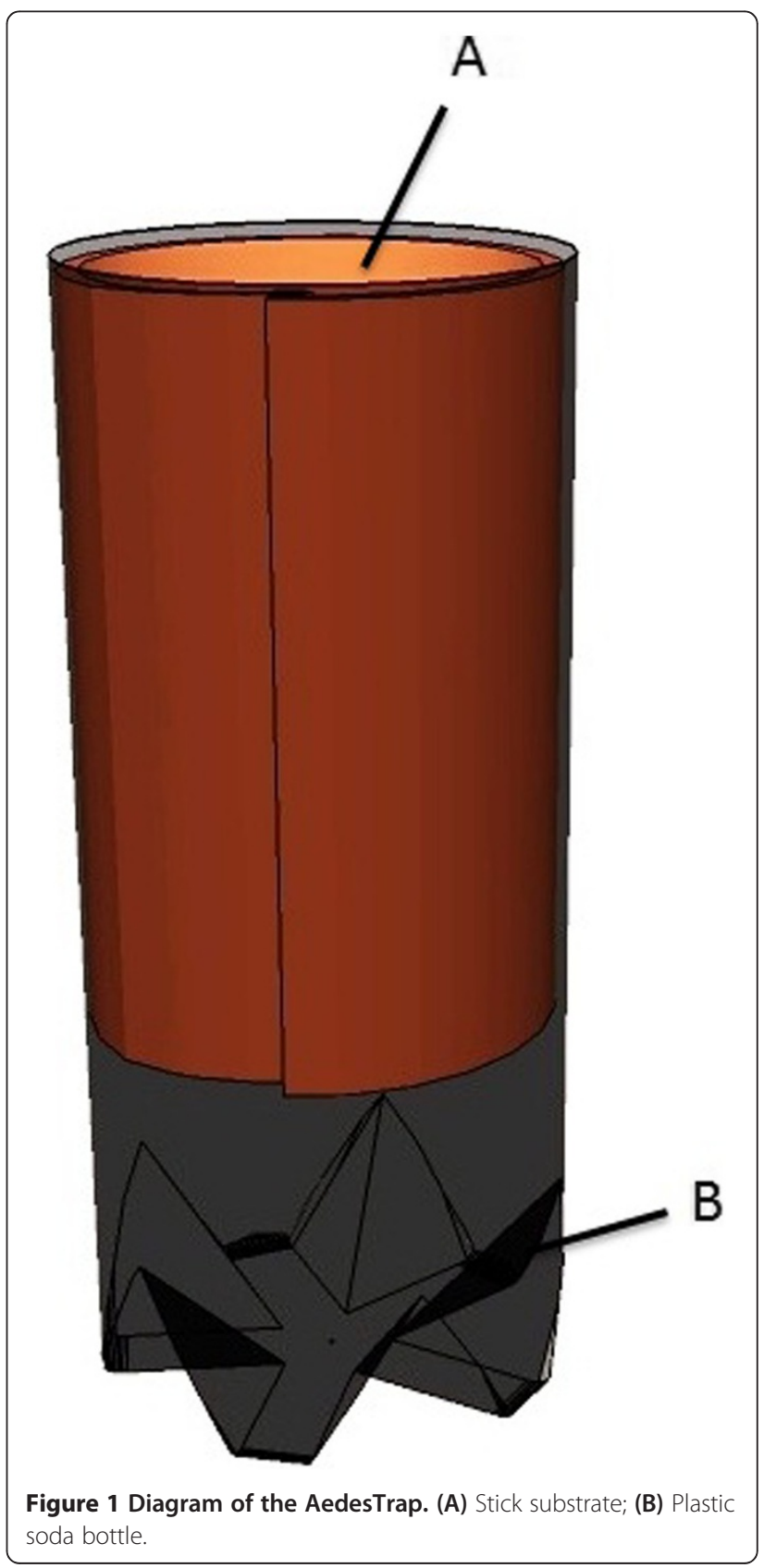


A second group of traps used in this study were ovitraps, modified from a model utilized by Recife City Council. This trap was made from a disposable plastic soda bottle (2 L), painted black and containing two wooden paddles $(5 \times 12 \mathrm{~cm})$ fixed vertically with metal clips, serving as an oviposition substratum.

Both trap types were filled with $1.5 \mathrm{~L}$ of tap water with $2 \mathrm{mg}$ of Bacillus thuringiensis israelensis granulated formulation (Bti), used as a larvicide to prevent the trap from becoming a breeding site. During the experiments, water, paddles and Bti were replaced every 28 days.

\section{Entomological survey}

The infestation level of Aedes spp in the study area was preliminarily evaluated based on the egg densities from 100 ovitraps (one per premise) distributed in the area, according to Regis et al. [19]. The inspection procedures of the entomological survey were verbally explained to residents. A statement of informed consent was obtained from residents and/or householders who allowed the installation of traps on their properties. The traps were installed in partially shaded outdoor areas (service area, open garage) georeferenced (Garmin model TREX VISTA HCX), and monitored from September 2008 to November 2008. Adult Aedes spp. frequency was estimated from a sample of $30 \%$ of eggs collected in the ovitraps. Mosquito identification was performed, using the taxonomy key for adults described in Consoli and Lourenço-de-Oliveira [20]. The high dispersion of Aedes eggs (95\% of positive traps) and heterogeneous egg distribution ranging from 1 to $3,439 /$ eggs/ovitrap $($ mean $=280.41 \pm 150.61$ eggs $/$ ovitrap) in the study area (Figure 2) allowed the random use of the area for experiments. Out of 758 identified mos quitoes obtained from the sampled eggs, 94.4\% were A. aegypti and 5.6\% were Aedes albopictus (Skuse, 1894).

\section{AedesTrap: performance in the field Detecting and capturing A. aegypti females}

57 premises were assessed ( $>100$ eggs in the previous infestation assay) from November 2008 to March 2009. Each site, received an AedesTrap that remained in the field for a 16 week period. The installation of the AedesTrap was carried out in sets of 12-13 premises per week, over a period of 28 days. Thus, four groups [1-4] of sites were formed, differing from each other only by trap installation period (first, second, third or fourth week). The first set of AedesTraps was installed on November 13 and the last on March 26. Each set of traps was monitored every 28 days, with four observation cycles being performed.

In order to confirm the infestation of a site an ovitrap was installed at each premise, serving as a sentinel trap (OVT-S), as described in Regis et al. [19]. In all the experiments, traps were installed in shaded locations protected from wind and rain, at $1 \mathrm{~m}$ above the floor and $2 \mathrm{~m}$ apart from each other.

During the study period, precipitation was registered per group/cycle, ranging from $6.4 \mathrm{~mm}$ to $45.1 \mathrm{~mm}$.

\section{Mosquito capture in indoor and outdoor areas}

The effect of AedesTrap installation (indoor or outdoor) on the capture of adults was evaluated at 28 premises, in which initial egg densities varied from 180 to 2,600 eggs/ ovitrap/cycle. One AedesTrap was installed indoors (laundry room, kitchen or bedroom) and one AedesTrap outdoors front or back yard protected by roof or tree at each premise. One OVT-S was installed in the outdoor area of each premise as an additional tool to confirm the presence of Aedes spp. The experiment was performed from April to July 2009, with traps being monitored in four 28 day cycles.

\section{Mosquito capture with different numbers of AedesTraps}

The relationship between the number of Aedes'Traps and number of captured mosquitoes was investigated by utilizing one or three traps/premise placed outdoors at 24 and 22 premises, respectively. The experiments were carried out in four cycles between April 2009 and August 2009. At time of installation, the infestation level at these sites, estimated by egg density/ovitrap/cycle, varied from 70 to 1,772 eggs at sites with one AedesTrap, and from 60 to 1,400 eggs at sites with three traps. One OVT-S was also installed in the outdoor area of each premise.

To verify whether the presence and the number of AedesTraps would influence the performance of the ovitrap, egg density from the ovitraps used in the above experiments was compared with 20 ovitraps installed at sites without an AedesTrap.

\section{Data analysis}

The proportion of positive traps served as the parameter to calculate the positivity index, reflecting the sensitivity of the trap. Traps were considered positive if they had at least one Aedes egg in the case of ovitraps and at least one $A$. aegypti adult in the case of AedesTraps. Trap efficiency was measured using the mean number \pm standard error (SE) of collected eggs or adults, calculated by the total number of individuals and divided by the total number of installed traps per cycle. Data normality was determined using the Shapiro-Wilk test and homogeneity of variance was tested using the Levene test. Normality and homogeneity for eggs distribution in group 4 were achieved using natural logarithm of values plus average. The comparative analysis of collected adults and eggs was performed using Analysis of Variance (ANOVA) and Tukey test a posteriori. The relationship between egg and female densities were analyzed using the Spearman correlation coefficient. All analyses were 


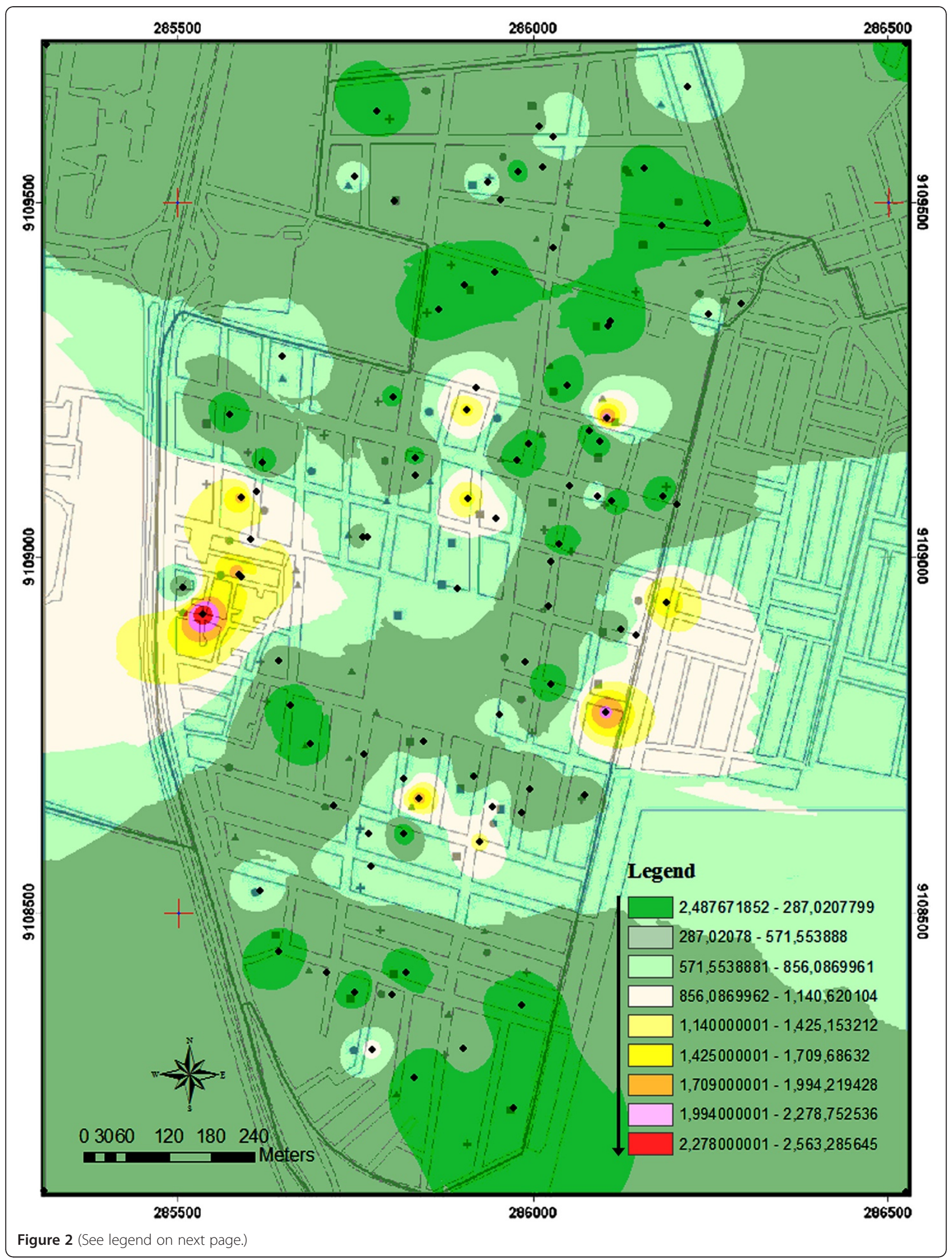


(See figure on previous page.)

Figure 2 Kernel map for spatial distribution of Aedes aegypti infestation in an endemic area of dengue. Data were based on egg densities (100 ovitraps sampled in two cycles of 28 days) in the neighborhood of Engenho do Meio, Recife, Pernambuco, between September 2008 and November 2008. Arrow indicates egg density gradient in the area.

performed with the STATISTICA 7.1 software, at a 5\% significant level.

\section{Results}

\section{AedesTrap performance}

\section{Detecting and capturing A. aegypti}

The positivity index of AedesTraps varied from 5.9\% to $57.1 \%$ with the average number of captured females of $0.54 \pm 0.07$ females/trap/cycle. There was no significant variation in the number of $A$. aegypti females captured among cycles and groups during this experiment. During the experiment (November 2008 to March 2009) cumulative precipitation for each cycle varied from $6.4 \mathrm{~mm}$ to $452.1 \mathrm{~mm}$.

In the same period, $71 \%$ to $100 \%$ of ovitraps were positive. No significant difference was found in the mean number of eggs collected among the four groups. However in Group 3 significantly fewer eggs were registered in cycle 2 compared to cycles 3 and $4(\mathrm{~F}=5.4661 ; \mathrm{GL}=$ $3,60 ; \mathrm{p}<0.005)$. Similar results were obtained in Group 4 , were register significantly great number of eggs in cycle 3 compared to cycles 1 and $2(\mathrm{~F}=6,50$; $\mathrm{GL}=3,39$; $\mathrm{p}<0.005$ ) (Figure 3).

In general, egg density increased in correlation with increasing rainfall (Figure 2). The total number of eggs collected was 1,627.9 \pm 495.8 /trap (Group 2; cycle 4) and $1,340.25 \pm 249.34 /$ trap (Group 4; cycle 3 ) when the rainfall of $403.3 \mathrm{~mm} /$ cycle and $392.1 \mathrm{~mm} /$ cycle, respectively. The lowest average number of eggs was obtained in Group 1 (302.1 $\pm 68.62 /$ trap; cycle 1$)$ when the accumulated rainfall was just $18.9 \mathrm{~mm}$. A low positive correlation $(\mathrm{N}=196, \mathrm{r}=0.2519, \mathrm{p}<0.05)$ was observed between the number of eggs and females collected in the sites (Figure 4).

\section{Other mosquito species}

During the above experiments a total of 270 specimens from at least three mosquito species were captured by the AedesTrap. Of these, $47.0 \%$ were A. aegypti, 39.3\% were Culex quinquefasciatus, $4.1 \%$ were $A$. albopictus and $9.6 \%$ were an unidentified species.

The proportion of mosquitoes captured by the AedesTrap varied significantly $(\mathrm{F}=19.53 ; \mathrm{GL}=3,78$; $\mathrm{p}<0.001$ ) among species. Individual comparison using the Tukey test showed that the number of captured $A$. aegypti was similar to $C$. quinquefasciatus $(\mathrm{p}=0.688)$.
However, both differed significantly $(\mathrm{p}<0.0001)$ from $A$. albopictus.

\section{Location of the AedesTrap: indoors and outdoors}

A total of $99 \mathrm{~A}$. aegypti females were collected over the period from April to July 2009, where the performance of the AedesTrap was evaluated indoors and outdoors. Capture rate was significantly higher $(\mathrm{p}<0.01)$ in outdoor areas (73.7\%) compared to indoor (26.3\%), with a mean capture rate of $0.7 \pm 0.1$ and $0.3 \pm 0.07 /$ AedesTrap, respectively. Overall, a total of $99 A$. aegypti females were collected over the period from April to July 2009. Thirty three percent of traps were positive outdoors, whereas $9.5 \%$ were positive indoors. Out of the 35 captured $C$. quinquefasciatus, 25 were registered outdoors.

The positivity index of the AedesTraps varied from $13 \%$ to $22 \%$ when installed indoors and from $32.1 \%$ to $47.8 \%$ when outdoors, whereas $95.6 \%$ to $100 \%$ of ovitraps were also positive, presenting an average of $709.6 \pm 51.6$ eggs/ovitrap/cycle. There was no positive correlation between the number of captured $A$. aegypti and the number of eggs at the sites $(\mathrm{N}=105 ; \mathrm{rs}=0.0331$; $\mathrm{p}=0.738)$.

\section{AedesTrap and mosquito capture numbers}

The presence of three sticky traps at premise significantly increased the number of $A$. aegypti females captured by the AedesTrap ( $\mathrm{F}=29.98 ; \mathrm{GL}=3,17 ; \mathrm{p}<0.01)$, especially during cycles 1 and 4 (Figure 5). From a total of 304 A aegypti females captured during this study, $25.7 \%$ were found as sites containing one trap and $74.3 \%$ at sites with three traps. A mean of $0.82 \pm 0.2$ and $2.63 \pm 0.27 \mathrm{~A}$. aegypti/AedesTraps/cycle females was captured using one and three, respectively, representing a three-fold increase in the number of females removed from the environment when three traps were used. A significantly higher number $(\mathrm{F}=12.76$; $\mathrm{GL}=1.173$; $\mathrm{p}<0.01$ ) of $C$. quinquefasciatus was also captured at sites with three AedesTraps. Table 1 shows the mean variation of mosquitoes captured in different cycles at sites having one or three AedesTraps. The installation of three AedesTraps at a site increased the possibility of discovering the presence of $A$. aegypti at the site. Using three AedesTraps/premise, $75.6 \%$ of the premises were positive, compared to $33.7 \%$ at sites with one trap. In the same period, ovitrap positivity was $99 \%$. 

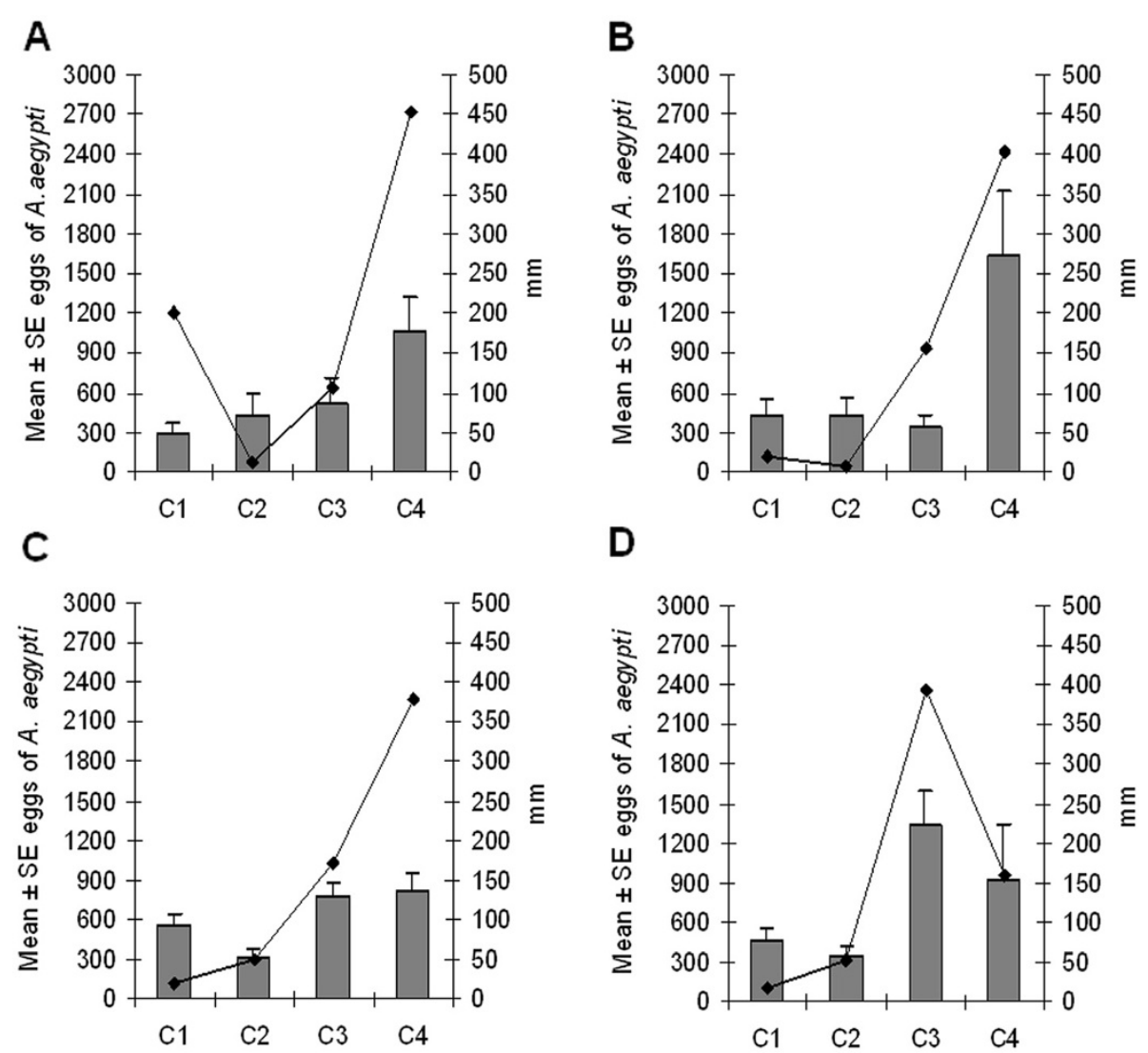

D

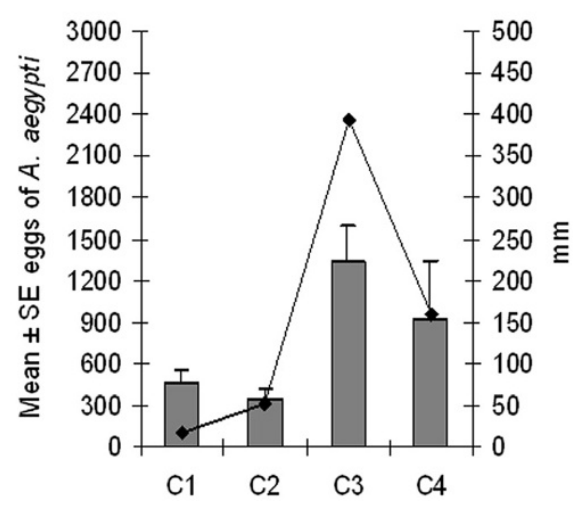

Figure 3 Precipitation and A. aegypti eggs densities in the neighborhood of Engenho do Meio, Recife, Pernambuco. Data are from November 2008 to March 2009. A, B, C and D represent groups of 12 or 13 ovitraps differing from each other only by trap installation period (first, second, third or fourth week). Each group was assessed in four cycles of 28 days. Line represents rainfall (mm) in the period. Bars are standard errors.

A positive correlation $(\mathrm{N}=86 ; \mathrm{rs}=0.39 ; \mathrm{p}<0.001)$ between $A$. aegypti female and egg numbers was only observed at sites with three AedesTraps (Figure 6). Egg density in ovitraps was not influenced by the number of sticky traps at the same site (Table 1). A similar mean number of eggs/ovitrap/cycle was registered at sites with

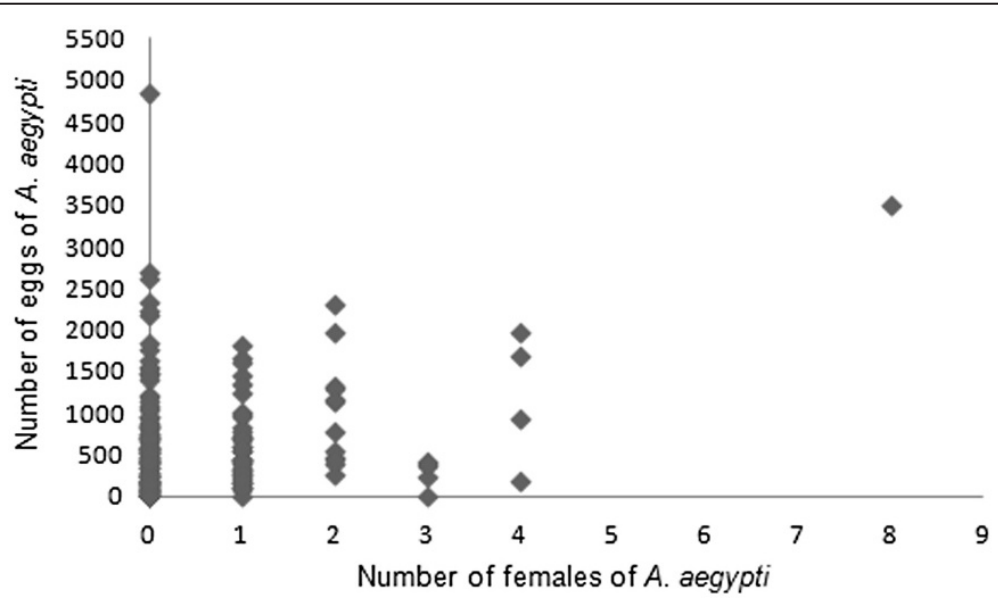

Figure 4 Correlation between eggs density and female capture. Spearman correlation between A. aegypti eggs and A. aegypti females collected in periods with distinct rainfall, during the period November 2008 to March 2009 in the neighborhood of Engenho do Meio neighborhood, Recife, Pernambuco. ( $N=196, r=0.2519, p<0.05)$. 




Figure 5 A. aegypti capture using one or three AedesTrap. Variance in capture success was calculated using the total number of Aedes aegypti/residence with one or three AedesTrap in the neighborhood of Engenho do Meio, Recife, Pernambuco, during four observation cycles from March to August 2009.

Table 1 Relative frequency of mosquito species, mean capture rate of AedesTrap and average egg number, in premise with one or three sticky traps, between March and August 2009, in Engenho do Meio neighborhood, Recife, PE

\begin{tabular}{|c|c|c|c|c|c|}
\hline \multirow[b]{2}{*}{ Number of AedesTrap/parameters evaluated } & \multicolumn{4}{|c|}{ Capture and catch cycles of Aedes spp. } & \multirow[b]{2}{*}{ Total/overall mean } \\
\hline & Cycle 1 & Cycle 2 & Cycle 3 & Cycle 4 & \\
\hline \multicolumn{6}{|l|}{ One trap } \\
\hline $\mathrm{n}^{\circ}$ of premises & 24 & 23 & 23 & 22 & 92 \\
\hline $\mathrm{n}^{\circ}$ of $A$. aegypti & 21 & 23 & 12 & 22 & 78 \\
\hline average number of & $0.88( \pm 0.32)$ & $0.96( \pm 0.63)$ & $0.5( \pm 0.25)$ & 0.96 & $0.82( \pm 0.2)$ \\
\hline females $( \pm$ SE)/trap & & & & $( \pm 0,27)$ & \\
\hline average number of & $0.88( \pm 0.32)$ & $0.96( \pm 0.63)$ & $0.5( \pm 0.25)$ & 0.96 & $0.82( \pm 0.2)$ \\
\hline females $( \pm \mathrm{SE}) /$ premise & & & & $( \pm 0,27)$ & \\
\hline$n^{\circ}$ of Aedes albopictus & 0 & 0 & 0 & 0 & 0 \\
\hline average number of females $( \pm \mathrm{SE}) /$ trap & NE & $\mathrm{NE}$ & NE & NE & NE \\
\hline average number of females $( \pm \mathrm{SE}$ )/premise & $\mathrm{NE}$ & NE & NE & NE & NE \\
\hline Eggs density Aedes spp./premise & $794.92( \pm 111.09)$ & $596.29( \pm 96.95)$ & $506.54( \pm 76.58)$ & $602.43( \pm 115.29)$ & $625.28( \pm 50.77)$ \\
\hline \multicolumn{6}{|l|}{ Three trap } \\
\hline $\mathrm{n}^{\circ}$ of premises & 21 & 21 & 21 & 19 & 82 \\
\hline$n^{\circ}$ of $A$. aegypti & 76 & 33 & 48 & 69 & 226 \\
\hline average number of females $( \pm \mathrm{SE}) /$ trap & $1.12( \pm 1.62)$ & $0.5( \pm 1.15)$ & $0.73( \pm 1.3)$ & $1.15( \pm 1.75)$ & $0.86( \pm 1.48)$ \\
\hline average number of females ( \pm SE)/premise & $3.45( \pm 0.53)$ & $1.50( \pm 0.46)$ & $2.18( \pm 0.48)$ & $3.45( \pm 0.65)$ & $2.63( \pm 0.27)$ \\
\hline$n^{\circ}$ of Aedes albopictus & 0 & 0 & 1 & 3 & 4 \\
\hline average number of females $( \pm \mathrm{SE}) /$ trap & $\mathrm{NE}$ & NE & $0.015( \pm 0.4)$ & $0.05( \pm 0.1)$ & $0.015( \pm 0.01)$ \\
\hline average number of females $( \pm \mathrm{SE}$ )/premise & NE & NE & $0.05( \pm 0.21)$ & $0.15( \pm 0.49)$ & $0.05( \pm 0.02)$ \\
\hline Eggs density Aedes spp./premise ( \pm SE) & $983.77( \pm 237.91)$ & $612.82( \pm 138.72)$ & $550.91( \pm 113.72)$ & $484.70( \pm 119.1)$ & $662.08( \pm 82.4)$. \\
\hline
\end{tabular}

$\mathrm{NE}=$ not evaluated $\mathrm{SD}=$ standard error 


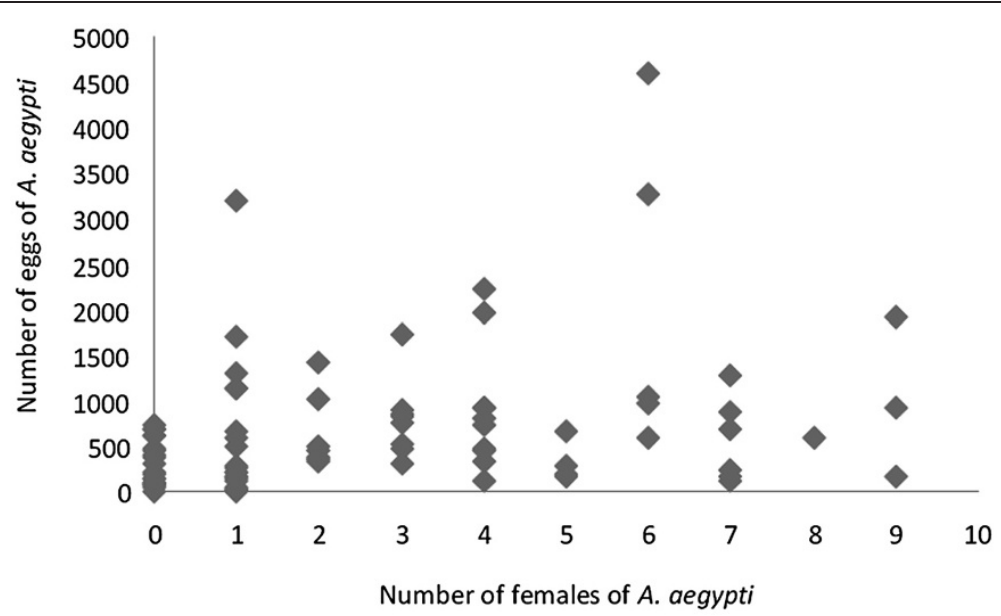

Figure 6 Spearman correlation between the number of $\boldsymbol{A}$. aegypti eggs and $\boldsymbol{A}$. aegypti females. Data were collected in sites with three AedesTraps/residence ( $N=86 ; r s=0.3920 ; p<0,001)$ in the neighborhood of Engenho do Meio, Recife, Pernambuco.

one $(625.28 \pm 50.77)$ and three $(662.08 \pm 82.4)$ AedesTraps. Egg densities did not vary significantly among ovitraps installed at the sites without an AedesTrap and at sites with one AedesTrap ( $\mathrm{F}=0.00069 ; \mathrm{GL}=1,165, \mathrm{p}=0.9799$ ) and three AedesTraps $(\mathrm{F}=0.9648 ; \mathrm{GL}=1,155, \mathrm{p}=0.75651)$. During this experiment rainfall varied from $235.9 \mathrm{~mm}$ and $771 \mathrm{~mm}$.

In all experiments, egg oviposition in water was observed by females stacked in the trap. Despite this fact no live larvae were found in these traps due to the use of Bti larvicide.

\section{Discussion}

The sticky trap designed in the present work is a simple and cheap construction, which captures $A$. aegypti females. These characteristics allow its large scale usage as a complementary tool in the control of this mosquito species.

The larger number of traps in the field significantly improved AedesTrap performance in collecting A. aegypti. The increase in capture rates ( 0.8 to 2.6 mosquitoes/premise) due to the number of available AedesTraps is similar to results obtained by Wiliams et al. [21] in Australia. According to these authors, sites with 4,6 , and 8 sticky traps captured significantly more A. aegypti per site than sites with 1 and 2 traps. The results of the present study demonstrated that there is a strong relationship between the number of AedesTrap available and the capacity to detect mosquito infestation at sites. At all sites, ovitraps were concomitantly installed and shown to be more sensitive than AedesTraps in detecting the presence of $A$. aegypti, independent of the number of AedesTraps utilized. Studies of the performance of MosquiTrap in Belo Horizonte [10] and in Rio de Janeiro $[4,14]$ also indicated the superior capacity of ovitrap in detecting the presence of mosquitos.
According to Honório et al. [14], although both traps are sought by females as an oviposition site, differences in their attractiveness may be one of the reasons for the low efficiency of MosquiTrap.

In previous works by this group (data not shown), utilizing AedesTraps and ovitraps with hay infusion in sites with high Aedes spp. infestation (>3,000 eggs/premise/ month), a high positivity rate (98\%) was registered for both traps, differing from what was observed here, where the positivity of ovitraps was always higher than that of AedesTraps. It is worth noting that besides differences in infestation levels between sites, the continuous presence of eggs in wood paddles, as well as volatiles originating from dead larvae and bacterial fermentation of water, may have influenced the attractiveness of the ovitrap. Other authors have also referred to the stimulating characteristic of Bti for Aedes spp. oviposition $[17,22]$.

Although the AedesTrap has been designed to collect adult $A$. aegypti, it also collected C. quinquefasciatus. The latter species is of great importance to public health in areas endemic for lymphatic filariasis, such as Recife in Brazil, as it is the vector of Wuchereria bancrofti, the etiologic agent of the disease [23]. The data presented here may serve as a starting point for further investigations on the use of AedesTrap to capture $C$. quinquefasciatus. This mosquito species has also been observed in other traps such as BGS-Trap [4] and Adultrap [24].

The higher positivity and capture rates of AedesTrap in outdoor areas confirmed the general consensus that this is the most appropriate location for the installation of traps, when the capture strategy is based on attracting A. aegypti females searching for oviposition sites $[4,25,26]$. In this study, about $30 \%$ of females were 
captured by AedesTrap exclusively outdoors relative to indoor. Similar behavior was also observed by Favaro and collaborators [27], in a study that utilized four MosquiTraps at each site and achieved 55\% trap positivity per site.

Studies performed with other sticky trap models have revealed considerable variations with regard to their performance in the field, with low capture rates generally observed. Throughout the study, there was variation between traps containing $A$. aegypti and the average number of captured mosquitoes per trap. These observations were in accordance with most studies on the performance of sticky traps to monitor and control A. aegypti. Possible elements affecting this variance are environmental factors $[24,28]$ and the peculiar behavioral characteristics of $A$. aegypti, such as "skip oviposition" [4,6,9,10,29]. In contrast, Chadee and Ritchie [7] described a high rate of female capture in Trinidad, West Indies, using both standard and double sticky traps. The performance of the double sticky trap was significantly superior to that of the standard model, particularly in urban areas.

The "death stress oviposition" behavior described by Chadee and Ritchie [11] when females became stuck in glue, was also observed in the present study. According to the authors, the stress caused by imminent death stimulates females to release their eggs.

The AedesTrap capacity of detecting and capturing $A$. aegypti during the evaluation of its performance was similar within different precipitation patterns, a finding that was different for ovitraps, which increased egg collection according to rainfall levels. A longitudinal study performed by Regis et al. [19], in which ovitraps were distributed in eight neighborhoods of Recife, showed a low oviposition rate in the dry season, increasing to a peak number of eggs at the beginning of the rainy period, in most areas, other than Engenho do Meio, where the present study was performed. In this neighborhood, a large number of eggs was removed from the environment with the use of more than 4,000 ovitraps per $\mathrm{km}^{2}$. This fact was considered as the probable reason why high egg density figures were not observed in the rainy season.

Methodological differences between this and other studies of adult sticky trap, particularly the time of traps spent in the field and the absence of attractive features in the traps used in this study, make data comparison impractical. In the present study, positivity rates and adult capture by AedesTraps used tap water, and, being monitored every 28 days did not show significant differences over the period of performance evaluation.

Studies using MosquiTrap in Belo Horizonte, in the state of Minas Gerais, showed that in the dry season (May-June), 31.5\% of the traps captured 0.11 females/ week [10], while in Mirasol, in the state of São Paulo, $70 \%$ of MosquiTraps (September 2006 - Mach 2008) were positive, with an average of 1.3 females/week throughout the study, with no discrimination between the mean observed in dry and rainy periods [14]. The Adultrap captured 0.18 and 1.6 females/day/trap when utilized in field tests in Foz do Iguaçu, in the state of Paraná, and in Olaria, in the state of Rio de Janeiro, respectively $[9,24]$. It is important to highlight that although daily or weekly observations offer more precise temporal information on infestation levels, they are logistically less viable in routine activities of entomological surveillance programs.

The use of reusable and low cost material to build traps stimulates the development of monitoring methods targeted at $A$. aegypti adults. In the present study, in which the disposable bottles were donated by restaurants, and traps were made by laboratory staff, the cost of the AedesTrap was less than U\$3. This is particularly important considering the possibility of using a great number of AedesTraps in the endemic area, removing females from the environment. It is important to notice that until now there are no sensitive methods able to precisely estimate A. aegypti adult population density. In addition, the AedesTrap proved to be operationally viable and sustainable for monitoring $A$. aegypti adults within the conditions of health services in Brazil. Moreover, the presence of trapped mosquitoes attracted the attention of the community, a fact that could be used to enhance their effective participation in Aedes control programs.

\section{Conclusions}

This study shows that the AedesTrap may be used as a tool for monitoring $A$. aegypti. The usage of at least three traps in outdoor areas allows the acquisition of more accurate data on the local adult mosquito population. This sticky trap was also capable of collecting other mosquito species such as C. quinquefasciatus and A. albopictus.

\section{Competing interests}

The authors declare that they have no competing interests.

\section{Authors' contributions}

CMRA, EMMS e JCC assisted with study design, logistical issues, field data collection. All authors were involved in data analysis and writing of manuscript. The final version of manuscript was read and approved by all authors.

\section{Acknowledgements}

Field assistance was provided by heath agents from Sanitary district IV (Recife). The research project was supported by Fundação Oswaldo Cruz (FIOCRUZ-PE) and Serviço de Referência para Controle de Culicideos Vetores (SRCCV) Centro de Pesquisa Aggeu Magalhães, by the Fundação de Amparo a Ciência e Tecnologia do Estado de Pernambuco (FACEPE), subject to contract APQ1323-4.00-08. We also thank the Serviço de Referência de Controle de Culiciedos Vetores do Centro de Pesquisa Aggeu Magalhães (Fiocruz-PE). 
Received: 13 April 2012 Accepted: 8 August 2012

Published: 7 September 2012

\section{References}

1. Resende MC, Silva IM, Eiras AE: Avaliação da operacionalidade da armadilha MosquiTRAP no monitoramento de Aedes aegypti. Epidemiol Serv Saúde 2010, 19:329-338.

2. Clark GG, Seda H, Gubler DJ: Use of the "CDC backpack aspirator" for surveillance of Aedes aegypti in San Juan, Puerto Rico. J Am Mosq Control Assoc 1994, 10:119-124.

3. Maciel-de-Freitas R, Lourenco-de-Oliveira R: Presumed unconstrained dispersal of Aedes aegyptiin the city of Rio de Janeiro, Brazil. Rev Saude Publica 2009, 43:1-12.

4. Maciel-de-Freitas R, Eiras AE, Lourenço-de-Oliveira R: Field evaluation of effectiveness of the BG-Sentinel, a new trap for capturing adult Aedes aegypti (Diptera: Culicidae). Mem Inst Oswaldo Cruz 2006, 101:321-325.

5. Facchinelli L, Valerio L, Pombi M, Reiter $P$, Costantini C, Della Torre $A$ Development of a novel sticky trap for container-breeding mosquitoes and evaluation of its sampling properties to monitor urban populations of Aedes albopictus. Med Vet Entomol 2007, 21:183-195.

6. Facchinelli L, Koenraadt CJM, Fanello C, Kijchalao U, Valerio L, Jones JW, Scott TW, Della Torre A: Evaluation of a sticky trap for collecting aedes (Stegomyia) adults in a dengue-endemic area in Thailand. Am J Trop Med Hyg 2008, 78:904-909.

7. Ritchie SA, Long S, Hart A, Webb CE, Russell RC: An adulticidal sticky ovitrap for sampling container-breeding mosquitoes. J Mosq Control Assoc 2003, 19:235-242.

8. Donatti JE, Gomes AC: Adultrap: Descrição de armadilha para adulto de Aedes aegypti (Diptera, Culicidae). Rev Bras Entomol 2007, 51:255-256.

9. Gomes AC, Silva NN, Bernal RTI, Leandro AS, Camargo NJ, Silva AM, Ferreira AC, Ogura LC, Oliveira SJ, Moura SM: Especificidade da armadilha Adultrap para capturar fêmeas de Aedes aegypti (Diptera:Culicidae). Rev Soc Bras Med Trop 2007, 40:216-219.

10. Gama RA, Silva EM, Silva IM, Resende MC, Eiras AE: Evaluation of the Sticky MosquiTRAPTM for Detecting Aedes (Stegomyia) aegypti (L.) (Diptera: Culicidae) during the Dry Season in Belo Horizonte, Minas Gerais, Brazil. Neotrop Entomo 2007, 36:294-302.

11. Chadee DD, Ritchie SA: Oviposition behaviour and parity rates of Aedes aegypti collected in sticky traps in Trinidad. West Indies. Acta Trop 2010, 116:212-216.

12. Fay RW, Elison DA: A preferred oviposition site as a surveillance method for Aedes aegypti. Mosq News 1966, 26:531-535.

13. Reiter P: Oviposition, dispersal, and survival in Aedes aegypti: implications for the efficacy of control strategies. Vector Borne and Zoo Dis 2007, 7:261-274.

14. Honório NA, Codeço CT, Alves FC, Magalhães MAFM, Lourenço-de-Oliveira $\mathrm{R}$ : Temporal Distribution of Aedes aegypti in Different Districts of Rio De Janeiro, Brazil, Measured by Two Types of Traps. J Med Entomol 2009, 46:1001-1014

15. Ordonez-Gonzalez JG, Mercado-Hernandez R, Flores-Suarez AE, FernándezSalas I: The use of sticky ovitraps to estimate dispersal of Aedes aegypti in northeastern Mexico. J Am Mosa Control Assoc 2001, 17:93-97.

16. Chen CD, Seleena B, Mohd MS, Chiang YF, Lee HL, Nazni WA, Mohd S: Dengue vector surveillance in urban residential and settlement areas in Selangor, Malaysia. Trop Biomed 2005, 22:39-43.

17. Stoops CA: Influence of Bacillus thuringiensis var. israelensis on oviposition of Aedes albopictus (Skuse). J Vector Ecol 2005, 30:41-44.

18. Liew C, Curtis CF: Horizontal and vertical dispersal of dengue vector mosquitoes, Aedes aegypti and Aedes albopictus, in Singapore. Med Vet Entomol 2005, 18:313-458.

19. Regis L, Monteiro AM, Melo-Santos MAV, Silveira JC Jr, Furtado AF, Acioli RV, Santos GM, Nakazawa M, Carvalho MS, Ribeiro PJ Jr, Souza WV: Developing new approaches for detecting and preventing Aedes aegypti population outbreaks: basis for surveillance, alert and control system. Mem Inst Oswaldo Cruz 2008, 103:50-59.

20. Consoli RAGB, Lourenço-de-Oliveira R: Principais mosquitos de importância sanitária no Brasil. Fundação Oswaldo Cruz: Rio de Janeiro; 1994.

21. Williams CR, Long SA, Russell RC, Ritchie SA: Optimizing ovitrap use for Aedes aegypti in cairns, Queensland, Australia: effects of some abiotic factors on field efficacy. J Mosa Control Assoc 2006, 22:635-640.
22. Santos SR, Melo-Santos MAV, Regis LN, Albuquerque CMR: Field evaluation of ovitraps consociated with grass infusion and Bacillus thuringeiensis var. israelensis to determine oviposition rates of Aedes aegypti. Dengue Bull 2003, 27:156-162.

23. Brito AC, Williams $P$, Fontes $G$, Rocha EMM: A comparison of two Brazilian populations of Culex quinquefasciatus (Say 1823) from endemic and nonendemic areas to infection with Wuchereria bancrofti. Mem Inst Oswaldo Cruz 1997, 92:33-36.

24. Maciel-de-Freitas R, Peres RC, Alves F, Brandolini MB: Mosquito traps designed to capture Aedes aegypti (Diptera: Culicidae) females: preliminary comparison of Adultrap, MosquiTRAP and backpack aspirator efficiency in a dengue-endemic area of Brazil. Mem Inst Oswaldo Cruz 2008, 103:602-605.

25. Dibo MR, Chiaravalloti-Neto F, Battigaglia M, Mondini A, Favaro EA, Barbosa AAC, Glasser CM: Identification of the best ovitrap installation sites for gravid Aedes (Stegomyia) aegypti in residences in Mirassol, state of São Paulo, Brazil. Mem Inst Oswaldo Cruz 2005, 100:339-343.

26. Lourenço-de-Oliveira R, Lima JBP, Peres R, Alves FC, Eiras AE, Codeço CT: Comparison of different uses of adult traps and Ovitraps for Assessing Dengue Vector Infestation in Endemic Areas. J Am Mosq Control Assoc 2008, 24:387-392.

27. Favaro EA, Dibo MR, Mondini A, Ferreira AC, Barbosa AAC, Eiras AE, Barata EAMF, Chiaravalloti-Neto F: Physiological state of Aedes (Stegomyia) aegypti mosquitoes captured with MosquiTRAPs TM in Mirassol, São Paulo, Brazil. J Vector Ecol 2006, 31:285-291.

28. Beserra EB, Castro FP, Santos JW, Santos TS, Fernandes CRM: Biologia e Exigências Térmicas de Aedes aegypti (L.) (Diptera: Culicidae) Provenientes de Quatro Regiões Bioclimáticas da Paraíba. Neotrop Entomol 2006, 35:853-860

29. Chadee DD: Dengue cases and Aedes aegypti indices in Trinidad, West Indies. Acta Trop 2009 , 112:174-180

doi:10.1186/1756-3305-5-195

Cite this article as: de Santos et al.: Evaluation of a sticky trap (AedesTraP), made from disposable plastic bottles, as a monitoring tool for Aedes aegypti populations. Parasites \& Vectors 2012 5:195

\section{Submit your next manuscript to BioMed Central and take full advantage of:}

- Convenient online submission

- Thorough peer review

- No space constraints or color figure charges

- Immediate publication on acceptance

- Inclusion in PubMed, CAS, Scopus and Google Scholar

- Research which is freely available for redistribution
C Biomed Central 